\title{
Fighting Illiteracy in the Arab World
}

\author{
Muwafaq Abu Hammud ${ }^{1} \&$ Amani G. Jarrar ${ }^{1}$ \\ ${ }^{1}$ Department of Development Studies, Faculty of Arts, Philadelphia University, Jordan \\ Correspondence: Amani G. Jarrar, Department of Development Studies, Faculty of Arts, Philadelphia University, \\ Jordan. Tel: 96-27-9552-2401. Email: aj8infinity@gmail.com
}

Received: May 15, 2017

doi:10.5539/ies.v10n11p116
Accepted: June 30, $2017 \quad$ Online Published: October 28, 2017

URL: https://doi.org/10.5539/ies.v10n11p116

\begin{abstract}
Illiteracy in the Arab world is becoming an urgent necessity particularly facing problems of poverty, ignorance, extremism, which impede the required economic, social, political and cultural development processes. Extremism, violence and terrorism, in the Arab world, can only be eliminated by spreading of knowledge, fighting illiteracy. The study shows that illiteracy rate among males in the Arab world is $25 \%$ for males, (46\%) for Females. Results of the study show that if the educational situation in all Arab countries does not change, illiteracy rates will increase in the Arab world, and the number of illiterates in the Arab world will reach 49 million in the category of age of 15 years, and by 2024,it may reach 5.5 million of youth (15 - 24 years). The study identifies factors affecting the rise of illiteracy in the Arab world, particularly: Low economic level of many Arab countries, the growing security, political turmoil and internal problems experienced by most Arab countries, Social reasons, and random policies and contradiction in the trends and areas of combating illiteracy. The study concluded that illiteracy has a significant impact on social behavior, and that democracy, political participation, violence, cultural development, respect, pluralism, and accepting diversity, are all affected by illiteracy. The study recommends that Arab governments must formulate clear strategies linked to development plans to save 100 million Arab citizens who suffer from illiteracy, and ignorance. Illiteracy is to be taken seriously because it entails misunderstanding democracy, lack of youth interest in political affairs, corruption, and therefore the absence of comprehensive reform programs.
\end{abstract}

Keywords: illiteracy, Arab world, extremism, violence, terrorism, political participation, political development

\section{Introduction}

Science is closely linked to the development process of any society, and is the basis of progress at various levels: economic, political and social. Thus education is a gateway to the era of knowledge and information, scientific and technological development, maintaining the process of development in all aspects of life. Therefore the talk about the phenomenon of illiteracy in the Arab world is an urgent necessity in trying to eliminate it regardless of problems of poverty, ignorance, extremism, which impede the required economic, social, political and cultural development processes. Extremism of terrorist groups, for example, can only be eliminated by further spreading of knowledge, education and training in the Arab world.

Illiteracy rates have increased in most Arab countries since the beginning of the 21st century, despite efforts by Arab governments to confront it, at the time the world has entered a new conflict of its kind to erase the new chapter of illiteracy; the "technological illiteracy" or "computer illiteracy", the Arab world is still struggling to combat illiteracy; as the inability to read and write (Noonpost, 2016).

Illiteracy is a form of human deprivation that reduces human ability to interact and participate, and is also an outright violation of the human right invested in laws and treaties around the world; known as the right of education and knowledge.

If knowledge is strength, illiteracy is an individual and societal vulnerability, because rich people in the future are rich in knowledge and information, and the poor are poor in knowledge, and have few skills and competencies (Shukri, 2016).

It is not satisfactory anymore measuring the development of societies by providing economic indicators such as per capita GDP or growth rates, the difference now is in the extent to which knowledge is acquired; and the ability to acquire knowledge is the fundamental determinant of the advancement of societies, in today's world, countries are measured by their different capacities for creativity, innovation, and knowledge production (Samih, 
2010).

The scientific and technological development that humanity has experienced in recent years, and the resulting explosion of knowledge, technological revolution and fundamental transformation in thinking patterns, means of production in all aspects of life, as well as the phenomenon of globalization and the unprecedented international competition in the field of knowledge economy, has put countries of the world, especially the third world countries in the situation of facing great challenges of being able to shift from a development perspective based on physical and natural resources to intelligent development based on knowledge resources, and knowledge production (Arab Knowledge Index, 2016).

Knowledge in today's world is a priority in major societal projects in various countries of the world, because it is the key to renaissance and development, and the main vehicle for achieving comprehensive development, knowledge of competence, and empowerment that is no longer a matter of choice. Therefore, development cannot be achieved unless knowledge becomes an integral part of the societal culture and value systems governing decision-making bodies (Arab Knowledge Index, 2016, p. 5).

Knowledge, as defined in this context, is not the sum of the facts that man knows, or the perceptions of self and surroundings; it is not just an accumulation of information, but a series of research, analysis, criticism that can produce new usable ideas and tools. (knowledge4all.com) Despite the efforts made by the Arab countries over the past decades in knowledge acquisition in various fields, it still suffers from a shortage that appears clearly in the field of knowledge production and dissemination within a weak knowledge system in its infrastructure, and its scientific research activity (Samih, 2010). And in spite of the large expenditure of Arab countries on education in the past decades, they have focused their educational policies on the quantity of education outputs rather than on quality of education, and therefore, they did not consolidate the skills and patterns of education related to the needs of the labor market, which affected the negative outputs of education in comparison to the requirements of the market, and thus resulted a high unemployment rates among graduates. Since 2004, the first Arab Human Development Report has identified the difficulties of the Arab development with three problems: lack of knowledge, lack of freedoms and lack of empowerment of women (The Arab Human Development Report, 2004). The efforts of all Arab countries have resulted in the reduction of illiteracy rates from $85 \%$ in 1950 to $60 \%$ in 1980 and $35 \%$ in 2005 and $19 \%$ in 2014, which means that one of five adults suffers from illiteracy, and this is considered one of the highest rates among the regions of the world. And according to the statistics of the Arab Organization for Education, Culture and Science (ALECSO), the number of illiterates in the Arab world is estimated at about 96 million out of 340 million in the Arab countries. The illiteracy rate among males in the Arab world is $25 \%$ for males, while it is (46\%) for Females (Illiteracy in the Arab world, 2017).

In the statement published by (ALECSO) on the World Human Rights Day in 2016, forecasts show that if the educational situation in all Arab countries does not change, the decreasing of illiteracy rates in the Arabs will slowly deteriorate, and the number of illiterates in the Arab world will be about 49 million in the category of age of 15 years and over by 2024, 5.5 million of which are youth with the age category ranged from 15 to 24 years. The Statistical Bulletin of the Arab Observatory for Education (ALECSO) also indicated in the first issue of 2016 that there was a slow decline in the number of illiterates in the Arab world between 2008 and 2015, from about 58 million illiterates to 54 million (Statistical Bulletin of the Arab Observatory for Education, 2016).

The Arab Observatory's statistics indicate that the Arab world will witness a limited decline in illiteracy over the next decade amidst the tragic situation in Syria, Iraq, Libya, Yemen and Somalia (Shukri, 2016). Wars and conflicts in the Arab region, especially after 2010, have severely damaged education and training systems, and have hindered development projects in a number of countries. More than 13 million students have lost their right to education because of current events in their countries (Madi, 2016).

\subsection{Problem Statement}

This study attempts to shed light on the phenomenon of illiteracy, which is an obstacle to the progress and development of societies. The phenomenon of illiteracy needs to be analyzed to deal with it seriously and in the correct and accurate scientific ways, and should be through identifying its causes to develop the appropriate solutions. Therefore, the real development of any society lies in its ability to develop and utilize its human resources.

\subsection{Importance of the Study}

The importance of this study appears in dealing with the issue of illiteracy at the present time in contrast with the current digital lifestyle, especially as we live in the era of knowledge and the remarkable development in information and communication technology, and also contrasted with the growing global interest in democracy 
and human rights, fighting corruption and improving economic conditions.

\subsection{Literature Review}

Educational reform in the Arab states has become a priority. Ruling elites, civil society, private sector and families are suffering from the high rates of illiteracy, lack of skills and bad quality of education of students. The region has launched various initiatives to deal with some burning issues.

Although adult education in the region has begun to take on other characteristics more prevalent in other parts of the world, which include providing people with the skills and knowledge needed to respond effectively to the growing challenges of new technologies and the information age, it is important to point that the "focus of adult education in the Arab region as a whole has been primarily on literacy, and most of the region still deals with adult education as a literacy issue (Hammoud, 2005).

Over the past three decades, countries in the Middle East and North Africa have made great progress in improving access to education. Between the years 1980 and 2008, average literacy rates in the region increased from $39 \%$ to $73 \%$, and the literacy gap between males and females narrowed considerably. Education is key not only to the competitiveness of economies but also to broader economic and social development, and to the functioning of political systems. Children of educated mothers tend to be healthier; access to education ensures social mobility,so that all available talent in the country is put to its best use, taking into consideration that political participation is broadened if the majority of the population is literate. From a purely economic perspective, education is the main vehicle to transfer general knowledge, which is increasingly becoming more important for competitiveness. It enables countries to adjust as they move up the development ladder and businesses evolving human capital needs. Despite significant progress achieved with respect to access to education in the region, the efforts have not yet been fully completed neither improved in quality of education, nor developed into higher economic growth, or in better employment opportunities for citizens (Hanouz \& Khatib, 2010).

However, despite of diverse and varied meanings and characteristics of literacy, literacy is a tool of communication; it is the ability to code and decode symbolic systems usually in the mother tongue, eventually transferring them to other languages as well. UNESCO (1979) defined literacy as: "The teaching or acquisition of reading, writing and numeracy skills to prepare persons" (Shenkut, 2005).

Current socioeconomic and political changes in the Arab world call for paradigm change,as literacy and adult education are no longer to be considered as a fundamental human rights, but also as a social movement towards the realization of that right in terms of the socioeconomic development of the Arab world. In this context, literacy and adult education should be used to strengthen respect for human rights and promote the right to differ, respect for the other and cultural diversity, which are the essential principles of democracy in the interconnected knowledge society. Therefore, emphasis should be placed on the political dimensions of literacy and the related challenges in order to create literate societies, rather than just making individuals literate (ISESCO, 2016).

Studies agree that illiteracy results from the simultaneous interaction of a number of factors. The most important of these are poverty, malnutrition, health problems, child labor, migration and lack of access to continuous learning and learning environments. These inequalities influence the social vulnerability of individuals, and vary significantly depending on gender, age, ethnicity and geographic location (Martinez \& Fernandez, 2010).

Social inclusion in this sense should be understood as a dynamic, multifactorial process that allows people to achieve a minimum standard of well-being (ECLAC, 2007).

\subsection{Structure of the Study}

This study is divided into three parts: part one presenting the introduction of the study, the second part introducing an overview of the causes and factors that contributed in the high rates of illiteracy in the Arab world, and the third part examines the effects of high rates of illiteracy in the Arab world on the individuals and the society, trying to come up with some appropriate solutions that are applicable on the ground, and also suggesting some recommendations to decision makers in an attempt to make a qualitative leap to reduce illiteracy.

\section{Factors Affecting the Rise of Illiteracy in the Arab World}

The continuing phenomenon of illiteracy in the Arab world is due to many reasons, the most important of which are:

First: Low economic level of many Arab countries: The low economic level of many Arab countries has contributed in the rise of poverty and unemployment, which led people not to send their children to schools, and thus their fate was in workshops and small industries that are unproductive for young people, and therefore high 
dropout rates. We can imagine the loss of Arab societies by turning these young people from development into obstacles, as they are building a large part of the future, and as they will establish families who are unable to help their children to learn, which will lead to a culture and social values of illiteracy. This category of children (young people) is most vulnerable to delinquency and exploitation, thus increasing the burden on their communities and their countries. The low economic level of many Arab countries has reduced the ability of governments to build schools and support poor families. Most Arab countries rely on one natural resource (such as oil in the Gulf States) as a major source of financing for their development projects, and as a result of the deterioration of the terms of foreign trade since the end of the last decade; this led to the decline in oil prices fluctuation up and down, resulting a decline in the proceeds of oil revenues of oil exporting countries, and fluctuations in their current accounts, which was reflected in the decline of development projects and low growth rates in most Arab countries and the decline of development projects in most Arab oil and non-oil countries, because of the close trading links with the Arab countries exporting oil, through the reduction of remittances of non-oil nationals from abroad, and the slow pace of aid to the development that are given to the Arab non-oil countries from the Arab oil-exporting countries as well as the decline in direct investment flows.

It should be noted here that the decline in the economic level of many Arab countries is also due to many reasons, including: the lack of clarity of government directives on investment issues, in addition the lack of clarity of the role played by the State in economic life and the relationship between the public and private sectors, as well as the low efficiency of economic management and the weakness of public institutions that oversees the implementation of development plans, as well as the almost complete absence of economic development policies in some Arab countries, the semi-permanent change of development plans with the continuous change of governments, and the instability of legislation governing investment in the majority of these countries (Samih, 2010).

The efforts of most Arab countries are still weak in finding other alternatives to their revenues and in diversifying their sources of income from other sectors such as telecommunications, the electronics industry or the industry in general. This has contributed to the problem of illiteracy.

Second: The growing security, political turmoil and internal problems experienced by most Arab countries: Wars, revolutions and political upheavals witnessed by most Arab countries since 2010, which some prefer to call the Arab Spring, although it is quite the opposite in reality, have contributed in the increasing number of illiterates and the deterioration of the level and quality of education in the Arab countries from Libya and Egypt to Syria, Iraq, Yemen, and Sudan, and Saudi Arabia. As the indicators and data available show that these countries have lost, at different rates, the benefits of decades of development in the areas of income, education, health and services, as is evident in the cases of Syria, Libya and Yemen. In other words, the Arab energies, especially the young, have not invested in the process of building human development, but have been introduced into historically conflicts to form a negative model of how the energies are wasted.

As a result of wars, many schools have been out of service as a result of their damage, or because they are used as temporary residence centers for citizens. In addition, the quality of education has been affected, and the internal efficiency indicators of the educational system have decreased, especially the average number of students in the classroom and the average number of students per teacher.

Despite the efforts of international and regional aid organizations, especially UNRWA and other institutions that play an educational role in refugee camps, the fear and panic of displaced families prevents many children, especially girls, from entering the education process. For example, in a country like Syria, the illiteracy rate as a result of the war has increased to more than $20 \%$ since 2011 , and the percentage of non-enrollment has increased to above $10 \%$. The dropout rate has risen to more than $30 \%$, therefore we are facing generations about a third of its children are illiterate (Abu-Halawa, 2016).

These wars and revolutions have consumed political and human resources for most Arab countries in an unprecedented manner, which has directly affected the fight against illiteracy in the Arab world, it has also contributed to narrowing the available development options, affecting the increase in expenditure on defense and security, reducing the allocation of expenditure on development projects, in particular those of the social services sectors related to the development of education, health and housing, which had a negative impact on the basic requirements for human development. It should be noted that this excessive overproduction has negatively impacted development, and the Arab States have not achieved the desired results in terms of strengthening their military power or enhancing their independence or control over their territories, resources and national wealth. This did not contribute significantly to the security and freedom of its citizens. Wars and revolutions also contributed in the decline of Arab aspirations for democracy, especially as democracy requires that every 
member of society to participate in thinking, governance, management, and decision-making. Democracy is a moral educational value, and without this proper construction of the individual, laws and procedures alone are not enough to build a democratic society. The process of building a human being and helping him/her to build abilities, expand options, develop skills and launch confidently towards the future, requires the expansion of one's education and knowledge and encouragement for innovation and creativity. The philosophy of education in most Arab countries has contributed in the aggravation of illiteracy in its various forms (alphabet, technological and civilization). The philosophy of education and teaching methods do not encourage creativity and thinking, this confirms the increasing problems of extremism and terrorism resulting from ignorance (Al-Otaibi, 2010).

Third: Social reasons: As a result of the deterioration in the security and political situation and the economic decline of many Arab countries, the rates of divorce, separation or imprisonment have increased. This has contributed to an increase in the number of families who are disintegrating into social ties and neglecting children to attend school.

Fourth: Random policies and contradiction in the trends and areas of combating illiteracy: Contributed in the slow reduction and suppression of illiteracy, while some educational policies focus on the educational content, some Arab countries are interested in the seats neglecting the educational quality, without realizing that the educational process must be integrated to address illiteracy. Until this day, we still see the absence of justice in the distribution of educational services among rural and urban areas in most Arab countries.

\section{Fifth: Other multiple reasons including:}

- The far distance between schools and residence, these distances prevent many families from sending their children to school or enroll in the educational process.

- Poor efficiency, quality and training of teachers, and lack of availability of the required number of teachers, especially in remote places, and because of low salaries and incentives provided.

- Low motivation among students, especially in an unsatisfactory learning environment due to overcrowded classrooms, lack of maintenance of school buildings and the content of educational curricula, which does not contribute in the development of students' skills, abilities and knowledge.

- To consider combating illiteracy as a matter of concern to the education sector alone.

\section{Ways to Reduce Illiteracy}

Despite the efforts exerted at the local, regional and international levels to reduce the phenomenon of illiteracy, it has not succeeded in reducing the problem of illiteracy. The problem of illiteracy will not end unless it is a joint Arab action between all governmental and non-governmental institutions, planning, financing, and pursuing. Above all, there is a real political will to fight illiteracy. Educational curricula in most of Arab countries are not related to the issues of society and do not aim at creating a citizen interacting with the issues of society and environment. This calls for radical changes and a real structure to find a new educational system corresponding with the developments and transformations in education, politics, society and economy, and providing the Arab citizen with the ability to live decent by providing adequate income. Policymakers in the Arab world should recognize that education is the key to achieving real and comprehensive development, and is the best way to reduce the extremism and blindness of some extremist ideas, ideologies and terrorist groups.

\section{Conclusion}

Fighting illiteracy is like a race to the future in a world where the true wealth of the nation is a human-being seen as a great asset. When the nation loses that balance, it loses control of its resources and wealth, independence of its decision, administration and identity. Illiteracy has a significant impact on social behavior of individuals. Such as democracy, political participation, education and society violence, exploitation of resources, cultural development, respect for the other, acceptance of pluralism, diversity and differences within society. Expanding the abilities, skills, thinking, education and knowledge of the individual can contribute to motivating people to work for the progress and development of their countries. And since about quarter of the Arab population suffers from illiteracy, Therefore, they are not aware of the principles of democracy and tolerance and fighting corruption. When political participation is increasingly discussed as one of the necessary requirements for the success of the democratic process, which entails manipulation of the fate of large segments of the population assuming their participation in political life .

\section{Recommendations}

In view of the above, it is recommended that:

1) Activating the role of media to play its role in the field of combating illiteracy, especially as it has great 
capabilities in the field of education and culture.

2) Renewing and developing the educational system as linked closely with the society and its issues, and to make it compatible with the requirements of the contemporary problems, and developing it as an educational system based on the skills of creative thinking, innovation, scientific research and constructive criticism, starting from the early stages of education,so that countries can build human capital capable of transferring and developing knowledge.

3) Arab governments must formulate clear strategies that can be applied on the ground, and are time-bound and linked to the development plans in a functional way to save 100 million Arab citizens who suffer from illiteracy, and ignorance.

4) Intensifying conducting research and studies that address the phenomenon of illiteracy to identify the real causes and consequences.

5) In light of the problem of illiteracy in the Arab world, it is difficult to achieve the desired reforms. Illiteracy means misunderstanding the principles of democracy, lack of interest in political affairs, and means the spread of corruption, and thus the decline of comprehensive reform programs.

\section{References}

Abu-Halawa K. (2016). Illiteracy and the Challenges of Achieving the Arab Knowledge Society: From Diagnosis to Prospective. Al-Tawat Journal, 28.

Al-Otaibi, M. A. (2010). Challenges of illiteracy and its current situation in the Arab countries. Retrieved from https://www.ahewar.org/debat/

Arab Knowledge Index. (2016). Retrieved from https://www.knowledge4all.com

ECLAC. (1997). Social Panorama of Latin America and the Caribbean. Santiago de Chile.

Hammoud, H. R. (2005). Illiteracy in the Arab world. Education for All Global Monitoring Report.

Hanouz, M., \& Khatib, S. (2010). The Arab world competitiveness review 2010. In World Economic Forum: Geneva.

ISESCO. (2016). ISESCO'S NEW LITERACY VISION. Publications of the Islamic Educational, Scientific and Cultural Organizations.

Madi, L. (2016). The Mechanisms and Methods of Literacy in the Arab World. Al-Thawat Electronic Magazine, $28,49$.

Martinez, R., \& Fernandez, P. (2010). The social and economic impact of illiteracy: Analytical model and pilot study. Anesthesiology, 104(4), 872-880.

Noonpost. (2016). How to eradicate illiteracy in the body of the Arab world. Retrieved from http://www.noonpost.org

Samih, M. (2010). Challenges of Arab Development. Canadian Center for Middle East Studies, Gilgamesh Cultural Society, Montreal, Canada.

Shenkut, M. K. (2005). Ethiopia: Where and who are the world's illiterates? Global Monitoring Report or to UNESCO.

Shukri, M. (2016). Illiteracy is still plaguing the Arab world. Journal of Electronic Thawat, 28, 10.

The Arab Human Development Report. (2004). Towards Freedom in the Arab World. The Arab Human Development Report of the United Nations Development Program (UNDP), Cairo 2004. Retrieved from http://www.un.org/esalrabs /ahdr2004

The United Nations Development Program (UNDP). (2005). The Arab Human Development Report 2005, towards the advancement of women in the Arab world.

United Nations Development Program (UNDP). (2014). Mohammed bin Rashid Al Maktoum Foundation, Arab Knowledge Report 2014, Youth and Knowledge Settling-United Arab Emirates. 


\section{Copyrights}

Copyright for this article is retained by the author(s), with first publication rights granted to the journal.

This is an open-access article distributed under the terms and conditions of the Creative Commons Attribution license (http://creativecommons.org/licenses/by/4.0/). 